\title{
CORPO EM MOVIMENTO: DOR E SUBJETIVAÇÃO EM MODALIDADES ESTÉTICAS DE ALTO RENDIMENTO
}

\author{
Thayara Paule Herrera Lima \\ Universidade Federal de São Paulo, Santos, São Paulo, Brasil \\ Ricardo da Costa Padovani \\ Universidade Federal de São Paulo, Santos, São Paulo, Brasil
}

\begin{abstract}
Resumo
A dor se manifesta com continuidade na vida de atletas, produz formas através das quais estes se relacionam com o esporte, consigo. Buscaremos compreender as modulações subjetivas da dor e significados advindos dessa experiência continuada nas perspectivas cognitivas e comportamentais em atletas de modalidades individuais cujo componente estético constitui indicador de desempenho e excelência. Este ensaio discute o papel das interpretações que modulam a figura do atleta e da dor, não reduzida a uma realidade estritamente biológica.
\end{abstract}

Palavras-chave: Dor. Interpretação. Estética. Desempenho.

\section{BODY IN MOVEMENT: PAIN AND SUBJECTIVATION IN HIGH PERFORMANCE AESTHETICS SPORT}

\begin{abstract}
The pain manifests continuously in athlete's life, produces modes whereby they relate with sports and themselves. We seek to comprehend the subjective modulations through pain and meanings from continued experience in cognitive and behavioral perspectives in athletes of individual modalities where the aesthetics components shows high performance and excellence. This essay discuss the figure of the athlete e and the pain, not reduced to a strict biological reality.
\end{abstract}

Keywords: Pain. Interpretation. Esthetics. Performance.

\section{CUERPO EN MOVIMIENTO: DOLOR Y SUBJETIVACIÓN EN MODALIDADES ESTÉTICAS DE ALTO RENDIMIENTO}

\section{Resumen}

El dolor se manifiesta frecuentemente en la vida de los atletas, y se produce de diferentes formas a través de las cuales esos individuos se relacionan con el deporte y consigo mismos. Se buscará comprender, en el presente trabajo, las modulaciones subjetivas del dolor y los significados que provienen de la experiencia continua, bajo las perspectivas cognitivas y comportamentales de aquellos que practican modalidades individuales, cuyos componentes estéticos constituyen un indicador de rendimiento y excelencia. Este ensayo pretende, además, discutir el papel de las interpretaciones que modulan la figura del atleta y su dolor, no reducido a una realidad estrictamente biológica.

Palabras clave: Dolor. Interpretación. Estética. Rendimiento. 


\section{Introdução}

\section{Corpos edificados}

Para abordar a temática do corpo, é necessário considerar a sua captura e enredamento por múltiplos discursos que moldam e criam formas de concebê-lo e relacionar-se com ele, através dele. Tais influências, por sua vez, situadas num dado espaço e tempo, propiciam e fazem arraigar conceitos, ideais e valores. Partiremos da perspectiva da teoria cognitiva, em especial a proposta por Aaron Beck, ainda que esta não possua uma discussão específica sobre o corpo, mas sim sobre esquemas cognitivos advindos de construções históricas que orientam as relações com o mundo, com o outro e consigo. Portanto, pode-se inferir que esta forma de se organizar também produzirá interferências em registros corporais.

Para tentar abarcar essa arqueologia do corpo e seus significados, Foucault (2013), apresenta diferentes perspectivas de um corpo já visto como sagrado, profano e tantos outros arranjos que lançam-no em diversas direções, fazem adentrar diferentes espaços sociais ainda que seu espaço seja outro, entre a negação e utopias desejadas: um corpo que se cria e remonta nas lacunas daquilo que nega e rejeita em si e aquilo a que aspira. "Os corpos se constituem entre discursos, instituições e corporeidade [...]. A paradoxalidade do corpo está em manter uma unidade entre o todo e as partes: corpo múltiplo, corpo uno, corpo sujeito, corpo objeto (VILLAÇA, 2009, p. 32)".

Uma mudança considerável se deu com a revolução industrial, possibilitando uma analogia do homem como uma máquina a ser aprimorada e sobre a qual se desenvolvem e incidem tecnologias que visam à construção de um determinado corpo, um determinado sujeito. "A ciência moderna, em todos os seus desenvolvimentos, participa fortemente dessa tentação e até mesmo a induz, propondo-se a corrigir as imperfeições do corpo e, antes de mais nada, sua imperfeição primeira, a fragilidade e precariedade." (VILLAÇA, 2009, p.33). Conjuntamente à pluralidade de acepções norteadoras do corpo e seus significados, há uma polifonia de saberes que versam sobre esse corpo, sua composição e transfiguração, o que constitui um desafio ao abordar esta temática, uma vez que há interferências nos diversos campos disciplinares, por exemplo, medicina, nutrição, educação física, psicologia e demais, que recorrem uns aos outros quando atuantes sobre este complexo corpo, reinventado em cada um destes discursos, com diferentes contornos quando dentro de cada uma dessas lógicas. Estudálo implica em entrar em contato com uma gama de recortes epistemológicos e enfoques relativos a temáticas e campos do saber. (GABRIELLI ; HOFF, 2007). É proposto pelas autoras também tomar o corpo como um "texto de cultura" (LOTMAN, 1979 apud GABRIELLI ; HOFF, 2007) partindo-se da compreensão de que um texto é uma combinação de signos a compor sentidos.

\footnotetext{
Nesse sentido, o corpo pode ser entendido como um texto de cultura, pois a identidade cultural - e, em tempos de pós-modernidade, as re-configurações identitárias - de um indivíduo está inscrita no corpo que a expressa por meio de gestos, danças, vestimentas, músculos, próteses etc. Trata-se de uma compreensão do corpo humano como resultado dos muitos elementos que conformam a cultura e que, portanto, extrapolam os âmbitos físico-biológico, psicológico ou sócio-antropológico. O corpo como texto é resultado de práticas culturais: suas representações revelam como a sociedade pensa que é, ou como ela gostaria de ser. Em suma, estamos discutindo o que somos, como vivemos e como, no corpo, registramos o fazer e as aspirações da sociedade (GABRIELLI; HOFF, 2007, p. 112).
}

Na perspectiva desse corpo em constante transformação/modificado e atravessado por uma pluralidade de fatores, explorar as relações estabelecidas entre o inteligível e o sensível, considerando o fenômeno da dor como sinal possível de um corpo que está próximo de ou em 
seu limite e o movimento de ir além deste, de tensionar um desconforto, uma fragilidade física ou mesmo emocional, em detrimento de um objetivo de aprimoramento, de um resultado considerado vitorioso em uma dada competição e ainda a integração deste estímulo comumente nocivo a uma realidade continuada se mostra um desafio para estudiosos desse corpo em movimento.

O fenômeno neste artigo trabalhado não é exclusividade daqueles que têm no esporte sua profissão. Torri, Bassani e Vaz (2007) discutem a interface corpo-dor-modelação corporal entre praticantes de academia de musculação. Destacam que a dor e o sofrimento se apresentam como algo inerente e desejável, um inimigo a ser combatido entre praticantes. A dor é vista como indicador de progresso e, portanto, resultado positivo do processo da modelação corporal. Soma-se ainda a valorização daquelas que suportam e superam a dor.

No caso dos atletas, a busca por aperfeiçoamento de uma dada capacidade tem como principal motivação atingir excelência. Intensificação e criação de potencialidades, expansão de limites, superação; a constituição do "eu" pautado em um intenso regime de treinamento e exposição. Nessa perspectiva, o atleta está exposto a um regime de estresse contínuo. Trata-se de um corpo que apenas descansa, para posteriormente poder receber um novo estímulo estressor. Ocorreu um processo de habituação de viver no limite do corpo, de explorar sua capacidade máxima, acompanhada de uma sensação de superioridade a cada superação (GONÇALVEZ; TURELLI; VAZ, 2012).

Durante todo este processo de modificação e criação de um corpo, até então desacostumado a esta experimentação atravessada por muitas intensidades e significados, a dor surge como componente relevante na equação. Consideramos a dor uma experiência sensitiva e emocional, que evoca desagrado, podendo estar associada ou não à lesão real. E é pela pluralidade de sentidos atribuídos a essa vivência, cuja presença torna-se rotina para atletas de alto rendimento, que ganha relevância a investigação da percepção dessa dor e os seus ecos com os processos de subjetivação.

Assim, pode-se pensar a dor enquanto fenômeno multifatorial cuja experimentação é modulada por um repertório prévio, mas também age sobre as formas como o atleta se estrutura para este encontro contínuo com um estímulo cuja definição evoca desagrado. Entretanto, quando enredado por outras questões, pode transformar-se em prazer (seja de aprimoramento, de vitória, superação e prestígio social) ou constituir-se um obstáculo em sua trajetória.

Nessa perspectiva, interessa-nos investigar as modalidades individuais, sem contato direto com adversário, na qual o componente estético seja requerido. $\mathrm{O}$ recorte individual se dá pelo entendimento de que a grupalidade é um fator importante na percepção do atleta a respeito dos próprios limites, possíveis sentimentos de co-dependência e demais crenças que podem emergir no contexto de um esporte coletivo, que não são o foco deste trabalho. A respeito da questão estética, interessa pensar a composição de uma cena, uma performance cuja execução bem sucedida depende do silenciamento de qualquer dor ou desconforto e, mais ainda, pede ao corpo que esconda determinadas marcas e revele elementos que interessem ser vistos, que traduzam estéticas, formas buscadas e valorizadas num dado meio esportivo.

Pensar o corpo, hoje, é pensar suas performances, numa visão que o contemple como um dos elementos constitutivos do amplo universo semiótico, em que se produzem as subjetividades. À medida que se altera a racionalidade do modelo que orientou o projeto moderno, quando o corpo era uma exterioridade a ser controlada, este assume, junto às mais variadas instâncias pessoais, intrapessoais ou coletivas, seu papel na produção da subjetividade. O corpo surge como carne e imagem, matéria e espírito simultaneamente (VILLAÇA, 2009, p. 35).

Muito tem se produzido considerando a dor e suas incidências sobre praticantes de esportes nas diferentes áreas. Este trabalho volta-se para as interpretações acerca desta experi- 
ência e, a depender do entendimento que se tem sobre esta vivência, mudam-se as formas de se relacionar com este corpo, através dele. Diante do exposto, e distanciando-nos dos trabalhos citados anteriormente, o presente buscará compreender as modulações subjetivas da dor e significados advindos dessa experiência continuada nas perspectivas cognitivas e comportamentais em atletas de modalidades individuais cujo componente estético constitui indicador de desempenho e excelência. Propomo-nos ainda, discutir o papel das interpretações que modulam a figura do atleta e da dor, não reduzida a uma realidade estritamente biológica.

\section{Reflexos de um atleta}

Conforme apontado por Silva, Rabelo e Rubio (2010), a dor no esporte destoa da dor representada na vida cotidiana. A dor carrega em si estruturas sociais e dos ambientes culturais. Tal afirmação evidencia a importância da atribuição significado no processo de interpretação da dor. Não se trata, portanto, tão somente do que almeja um competidor, mas também o quanto é contaminado, afetado por um imaginário de pessoas pertencentes ao seu círculo profissional e pessoal que define o que é ou não pertinente e aceitável para um atleta que visa predicados positivos, valorizados, respeitados. Rubio (2012) discorre acerca da moral e da ética esperadas de um atleta. Adentramos assim o terreno dos valores ao considerarmos uma dada moral internalizada, adotada por um atleta que, a partir deste conjunto de referenciais, de acepções, norteia-se dentro do seu esporte em termos de condutas e comportamentos.

O atleta de alto rendimento contemporâneo ocupa um espaço mais próximo do espetáculo e do lazer. Seus feitos são capazes de levar multidões a estádios e ginásios, em momentos de espetáculo, ou causar comoção e dor em caso de acidente ou morte [...] Na relação entre o ego e o desempenho de papéis sociais, muitas vezes o atleta se vê identificado apenas com a figura espetacular sugerida pela condição de esportista - aquele capaz de realizar grandes feitos (LIMA; RUBIO, 2016, p.92).

Aqui, outro componente se apresenta na construção e incorporação dos processos identitários de um atleta, os limites do socialmente aceitável para ele. Isto interfere inegavelmente na relação estabelecida com a dor seja no momento de treinamento ou em competição. Estando nitidamente estabelecidos os critérios para que se pertença a um grupo de elite ou estar aquém dessa realidade, cabe ao competidor fazer o manejo das dificuldades impostas por seu corpo (no que diz respeito a questões tanto físicas quanto mentais) considerando um emaranhado de significados que o arrastam para um determinado polo a cada dor, seu ocultamento ou demonstração, a cada lesão.

Freire e Pereira (2009) abordam especificamente a questão das crenças estereotipadas acerca dos atletas que se lesionam. Para eles, machucar-se em um ambiente competitivo pode significar não só um problema de saúde, mas também derrotas inesperadas e consequentes perdas econômicas. Nesta perspectiva, o atleta se vê obrigado a sempre demonstrar que é forte o suficiente para suportar o ritmo que lhe é imposto, em especial quando os seus companheiros e adversários o estão fazendo. Evitam ser conhecidos como frágeis ou preguiçosos, o que indica, pelo menos implicitamente, a existência de estereótipos sobre os atletas lesionados. Silva e Ferreira (2016) expandem esta preocupação acerca da demonstração ou ocultamento para outros grupos que praticam esportes de modo não profissional. Revelam que suportar as dores, agudas ou crônicas, representava uma posição de prestígio, uma indicação de virilidade ao passo que queixar-se, poderia representar uma posição não espera e deseja para um determinado grupo. As considerações apontadas no estudo de Silva e Ferreira (2016) ajudam a explicar como modelos mentais podem ser construídos por atletas e ídolos em relação ao que se espera de um atleta de elite. Modelos mentais pouco flexíveis podem favorecer padrões 
interpretativos mais rígidos e, portanto, mais sujeitos ao sofrimento e adoecimento físico e mental.

Pinheiro et al (2011) ressalta que as crenças que permeiam e modulam as subjetividades de atletas não são intrínsecas ao sujeito, mas antes passam por um crivo social que dá elementos e pistas dos valores e crenças a serem adotados, lapidados ao longo de uma trajetória esportiva, seja qual for o esporte, com variações condizentes a cada modalidade. Nesta perspectiva, os autores deixam evidente que a cultura do excesso, do risco, da dor não é exclusiva do esporte masculino e que o esconder e disfarçar a dor e ou a lesão esportiva constituem formas comuns de atletas lidarem, independente do gênero. Portanto, a naturalização desse processo evidencia que estão dispostos a colocar seus corpos em risco. Tais considerações reforçam o impacto da intepretação e não da situação em si no comportamento humano.

Com as modalidades que requerem certo componente artístico, como algumas ginásticas e certo tipo de dança, não é diferente. Contam com as mesmas aspirações sociais de determinada estética corporificada, com o diferencial de que certas marcas decorrentes do percurso de criação deste corpo em questão devem ser escondidas. Há uma preocupação tão expressiva quanto, ou ainda maior, em fazer com que este corpo tire de cena o registro daquilo que não interessa ao espectador: um componente inerente à constituição de sua performance, mas que ressoa com padecimento e nega a figura espetacular que se quer e tenta sustentar.

É relevante ressaltar que tais estereótipos transcendem os próprios atletas e demais integrantes do meio esportivo. Uma vez que é o esporte é também um produto a ser consumido por espectadores, torcedores e mesmo patrocinadores, o imaginário que se tem sobre como deve ser um atleta é um agravante, mesmo que este ideal seja distante de uma realidade possível, saudável, mas que sustenta expectativas de superação de limites, recordes, considerações essas já notadas por estudiosos do esporte (FREIRE; PEREIRA, 2009; SILVA et al, 2010; LIMA; RUBIO, 2016). Neste mesmo estudo, Freire e Pereira (2009) apontam que uma das distinções versa sobre o envolvimento com o universo esportivo, com separação dos participantes em "não envolvidos" com a área esportiva, "praticantes" (o critério da prática esportiva permitiu ainda alocar os participantes em amadores e profissionais) e "não-praticantes" de esporte. Pode-se perceber confluências e dissonâncias que permeiam as crenças de todos que possuem algum grau de envolvimento com o esporte.

Retomando a questão pedagógica sobre o corpo citada por Torri, Bassani e Vaz (2007), Thomazini, Moraes e Almeida (2008) e Gonçalves, Turelli e Vaz (2012), ao se iniciar uma determinada prática esportiva, existem vários aparatos que vêm modular esta vivência, ensinar um fazer que leve aos resultados almejados. Passa-se também por uma pedagogia acerca da dor e, mais do que isso, torna-se sinônimo de experiência e avanço no caminho desejado acostumar-se com ela e utilizar-se dela. Para os atletas, esta demanda é ainda mais presente, pois determinadas conquistas, sejam de ritmo de treinamento ou de novas e aprimoradas habilidades, vêm com o aprendizado acerca da dor, inerente ao processo bioidentitário de tornar-se atleta. A partir daí, o atleta tem mais um componente a ser equacionado no que tange demanda e autoimagem, com as estratégias mentais compondo possibilidades de recurso.

Está em jogo uma educação do corpo em que o trabalho pedagógico que ali acontece tem por função substituir um corpo não acostumado [...] por um corpo estruturado e fisicamente remodelado conforme as exigências da prática em questão. Sendo assim [...] criam estratégias para sublimar a dor e suportar o sofrimento. (THOMAZINI; MORAES; ALMEIDA, 2008, p. 285).

\section{Modos de operar com a dor}

Nas teorias cognitivas, como por exemplo, no modelo beckiano (BECK; ALFORD, 2000; KNAPP; BECK, 2008), levam-se em consideração os registros advindos das cognições, 
afetos e comportamentos compondo as diferentes formas de delinear subjetividades. A partir daí, há uma estruturação de informações em redes associativas e esquemas que esboçam e integram modelos de realidade nos quais padrões comportamentais interferem num dado fluxo cognitivo, bem como padrões cognitivos relativamente estáveis evocam padrões de respostas. Crenças basais e formas de agir no mundo que remetem a um outro, igualmente visto e constituído nestes termos. A tríade cognitiva, proposta por Beck (2000) traz esses aparatos mentais que estruturam o self: como me vejo, como vejo o outro e o mundo ao meu redor. Quando se fala em cognição, entretanto, não se entende uma estrutura imaterial cujo corpo seria aparato necessário, mas que este justamente seria condição primeira de um $E u$ que se cria e investe a partir daquilo que permite experimentações com o que está no mundo. Corpo e processos identitátios cujas modulações carregam memórias constituídas por vivências sucessivas com maior ou menor sensibilidade para determinadas situações. Todo esse conjunto culmina em variados processos de subjetivação.

Ao considerar a cognição, pensa-se também a possibilidade de sua modulação por intermédio de algumas ferramentas e pontos de interferência, meios de confirmar ou readequar interpretações sobre determinados aspectos de uma realidade experimentada pelo sujeito de modo que este possa estabelecer relações menos custosas (BECK; ALFORD, 2000; KNAPP; BECK, 2008). Para um atleta, submetido a altos níveis de estresse e intensas cobranças físicas, emocionais e mentais, a viabilidade de outros processos interpretativos e de atribuição de significados pode ser relevante. Assim, as estratégias mentais e a atenção são respectivos exemplos que podem tanto incidir sobre pensamentos, imagens mentais ou mesmo sensações (emoções e alterações fisiológicas) que possam ser aflitivos, angustiantes e cuja captura pode ser decisiva para um resultado de determinada etapa vivenciada pelo atleta. No caso das imagens mentais, pode ser interessante questionar sua validade e tentar readequá-la quando seus elementos validam uma visão extremada de uma determinada situação, aspecto amplamente discutido por teóricos cognitivos (BECK; ALFORD, 2000; CAMINHA; VASCONCELLOS, 2003). Assim podem ser também os pensamentos, cujo conteúdo pode levar a vivências de difícil sustentação e pouca possibilidade de manejo, de cinesia quando numa realidade enrijecida.

Acerca da atenção e estratégias mentais, estudiosos da área do esporte (SILVA et al 2010; AZEVEDO; SAMULSKI 2003; WOLFF, 2015) destacam que estas seriam aliadas dos atletas e seu desempenho desejado, uma vez que mudar ou mesmo reduzir o foco de um estímulo pode significar vislumbrar de um modo diferenciado o momento, podendo facilitar um gesto, um movimento e a precisão com que serão executados, possibilidades estas de grande relevância para as modalidades estéticas. Por outro lado, a catastrofização e o evitamento estariam associados a uma maior dificuldade em desvencilhar-se do estímulo doloroso e prosseguir com uma determinada demanda. É também apontada a questão da consciência corporal enquanto covariante de possível predição tanto para resposta à dor quanto para o desempenho esportivo (SILVA et al, 2010).

Ao investigar a representação da dor entre atletas, Silva et al (2010) ressaltam o papel da subjetividade no processo da manifestação e intensidade da dor e como se apresenta como uma companhia constante na vida do atleta. Pensando que se trata de um elemento constante, o atleta aprende a reconhecer sua forma de expressão podendo aceita-la como indicador importante de risco ou apenas ignorá-la. Nesse processo de avaliação da dor, levam-se em consideração os processos cognitivos conscientes e inconscientes e o uso das estratégias compensatórias como forma de negar algo mais profundo e organizar da personalidade.

Pinheiro et al (2011) se voltaram para algumas estratégias empregadas por atletas também. Para os autores, há uma tendência de gestão da dor de modo privado: 
Esconder, disfarçar a dor são estratégias frequentemente adoptadas por atletas de ambos os gêneros para lidarem com a dor e/ou lesão. Sendo a dor e a lesão vistas como algo com conotação negativa, como um verdadeiro inconveniente por parte dos treinadores, colegas e até público, os/as atletas tendem a ocultar a dor e/ou a lesão para assim evitarem julgamentos ou críticas (PINHEIRO et al, 2011, p. 105).

É apontado no estudo ainda que "frequentemente recorrem a analgésicos para suportarem a dor, negligenciando muitas vezes os efeitos que tais substâncias terão sobre a sua saúde a longo prazo (PINHEIRO et al, 2011, p. 106)". É discutido ainda neste trabalho a existência de uma cultura de risco a qual levaria os atletas a comportamentos disfuncionais no que diz respeito à preservação de si.

Em outro estudo, Azevedo e Samulski (2003) se voltaram também para o uso das técnicas psicológicas de controle da dor. Partindo também de um estudo comparativo, entre atletas e não-atletas, tanto do sexo feminino quanto masculino, constatou-se o emprego de técnicas cognitivas e comportamentais separadas em dois grandes grupos: técnicas maladaptativas, as quais fariam uma regulação inadequada de controle da dor no sentido de piora dos parâmetros relacionados à dor, e as adaptativas, como por exemplo, as motivacionais e regulação da tensão corporal. Os achados de Azevedo e Samulski (2003) reafirmam a complexidade dos aspectos psicológicos nas diferentes formas de expressão da dor e deixam evidente a influências da metacognição na criação de estados mentais favoráveis àquilo que se almeja. Podem-se observar múltiplos movimentos estabelecidos entre este corpo vivido que constitui o atleta com todos os conjuntos referenciais que o norteiam e a incorporação de novos elementos, os quais incidirão direta e constantemente sobre esse indivíduo: uma nova rotina, sensações, aspirações, expectativas, cobranças, afetos e novas relações que o farão movimentar-se, deslocar-se e se reorganizar.

Assim, tanto quanto investigar os recursos utilizados para estes momentos de maior estresse interessa a compreensão acerca do que é vivenciado, as categorias nas quais são colocados pensamentos, imagens e sensações, enfim, todo um universo representacional que diz da realidade singularizada de um determinado atleta.

Intermediando este esboço corporal e sendo por ele alterado, estão as interpretações daquilo que é vivenciado em termos de formas, representações e a própria mecânica dos movimentos. Significação e integração de elementos por um eu que se transfigura em um duplo movimento de acolhimento e rejeição de aspectos de si em busca de um ideal de esporte, de dança.

\section{Compondo uma cena}

Se, de modo geral, a concepção de atleta que se tem coloca o esportista em tensionamento constante com aquilo que pode e deve demonstrar, em uma modalidade que requer o refreamento de uma dor que antes já não era aconselhável mostrar, mas agora torna-se proibido e passível de decréscimo de pontuação um movimento, um gesto que destoe de uma montagem pré-concebida. Pode-se dizer que todo atleta realiza uma performance ao jogar, independente do esporte, pois identificam-se elementos que caracterizam um modo próprio de desempenho, uma forma de se apresentar que venha a compor com a imagem pretendida, de proeza esportiva. No caso das modalidades com componente estético, entretanto, gostaríamos de trazer um sentido de performance com familiaridade e ressonâncias nas artes, na dança, onde há um cuidado com o que será apresentado de forma a garantir enredamento, cadência de gestos cuja precisão será provada através da sutileza com que será desempenhada e onde o corpo que se apresenta pode estar imerso em um rigor ainda maior acerca das marcas que pode carregar ou precisa esconder, juntamente com outras partes da subjetividade (GONÇALVES; TURELLI ; VAZ, 2012). 
Nesse sentido, podemos aproximar algumas questões que emergem ao se considerar o campo da dança com esses esportes, pois em ambos há um rigor estético a ser inserido num conjunto de movimentos bastante precisos a serem executados por um determinado corpo. Muitas podem ser as entradas para se abordar a temática do corpo e, assim como o esporte faz com que um corpo se depare com uma realidade até então inexplorada de aptidões, assim a dança o faz, dentro do seu próprio universo de signos.

São diversas as relações estéticas mediando a realização da dança e tantas outras categorias que se apresentam ao corpo que se dispõe para esta atividade, convocando-o para agenciar estes e tantos outros elementos e a si próprio, que funde-se e ao mesmo tempo torna-se algo mais que a simples somatória destas categorias (REIS; ZANELLA, 2010). Essa reinvenção constante ocorre de forma semelhante nos atletas, cujos corpos e processos identitários se desenham pela modalidade escolhida.

Distante de se tratar apenas de processos racionais e conscientes, muitos são os elementos de interação e incidência na realização de uma performance. Uma parcela do será executado corresponde ao que foi exaustivamente ensaiado, mas parte foge do controle e se faz entre o esperado e a vivência em ato, cujos esboços se dão por um "eu", mas também em cocriação com espaço e espectadores que ditam uma determinada tonalidade para o momento.

\begin{abstract}
A bailarina deixa então o corpo falar, mas não de qualquer maneira, e sim na linguagem específica daquele gênero de dança, pois sua consciência corporal é semioticamente mediada pelos movimentos, além, é claro, de também o ser pelas sensações, emoções e pensamentos [...] Vai além da simples descarga motora da emoção, pois essa é transformada por meio da elaboração estética. Nessa interação com a música, o corpo da bailarina se constitui como um corpo dialógico [...] Além da música, da emoção, da técnica da bailarina, o contexto social em que ela se encontra, ou seja, a qualidade do espaço, o tempo e a presença da plateia constituem modo como a dança se objetiva. A apropriação dos sentidos socialmente produzidos nessa relação estética com um outro, em um determinado tempo e espaço, constitui a própria bailarina e suas possibilidades (REIS; ZANELLA, 2010, p.152, 153).
\end{abstract}

Este controle da dor e do desconforto, nestes esportes, elevados a um nível diferenciado na qual impera a sutileza e fluidez, uma cadência de um corpo com o que ele cria e desempenha numa dada performance e o não lugar daquilo que nega a cena a ser apresentada, a saber o desconforto, a dificuldade, a própria dor. A exemplo disto, Gonçalves, Turelli e Vaz (2012) discutem o balé:

No balé, expressão artística cujo material é o movimento corporal, faz-se comum a formação e exibição de corpos retilíneos, flexíveis, esguios e fortes. A disciplina corporal é marcante nesta prática que se materializa em longas sessões de aulas e ensaios. A realização dos movimentos supõe perfeição técnica e, apesar das características duras, o balé procura exaltar a leveza, a delicadeza e a beleza, atributos associados ao feminino (GONÇALVES; TURELLI; VAZ, 2012, p. 143).

\title{
Considerações finais
}

Com o presente trabalho ensejamos evidenciar o processo interpretativo nas diferentes formas de expressão da dor entre atletas de alto rendimento. Uma experiência atravessada por todos em algum momento, adquire diferentes tonalidades de acordo a tolerância em relação a ela e os sentidos atribuídos às diferentes dores que podem ser vivenciadas por alguém. Quando um elemento que compõe a vivência e o aprimoramento profissionais, e não mais um estímulo a ser eliminado, os contornos que se delineiam ganham especial interesse. Abarcamos assim o cerne da teoria cognitiva que versa sobre as interpretações de ocorrências serem determinantes e não as ocorrências em si. As leituras múltiplas de um corpo atravessado por 
algum tipo dor e os movimentos esboçados a partir daí: enfrentamento, negação, desistência. Todas possibilidades executáveis a depender do que se vislumbra, do que se acredita como limite, como intransponível.

Não se trata de obtenção de prazer utilizando-se da dor, ainda que o prazer seja componente desta complexa trama de apreensões, mas quando remete a ideias de melhoramento, prestígio, de ser vitorioso (Rodriguez, 2017). A dor aqui aparece diretamente proporcional à visibilidade e os ganhos advindos daí como melhores oportunidades e o desenvolvimento de um ego que passa a identificar em si muitos dos ideais que seduzem e fazem adentrar num dado ritmo de treinamento. Aqui, a visibilidade emerge como um conceito balizador: enxergar a dor e a partir desta visão tê-la como percalço ou impulso de uma conquista; ser visto pelo outro, o que valida toda uma trajetória de esforços; a não permissão que o outro veja associada à imagem deste ego vitorioso, fragilidade e, nos esportes estéticos, levar esta ilusão a um nível de completo apagamento das marcas desta companhia, por vezes, inconveniente.

As trajetórias de um atleta são permeadas por particularidades a serem equacionadas constantemente; sua performance e as ressonâncias desta com o espetacular, que levam a diversas expectativas sobre ele, por parte do público que acompanha e torce, por parte de patrocinadores, de si próprio e daqueles mais próximos a ele também. Podemos expandir a dor para um estado para além de um acometimento biológico, também como resultados das sucessivas cobranças que enredam este corpo: encontrar-se em um constante dever, uma permanente lacuna entre o que se é atualmente e o corpo e limites que se quer alcançar; as dificuldades de habitar este modo de contínua negação de si, uma vez que estabelecer um novo recorde, uma nova conquista implica colocar-se na posição de um vir a ser ideal a que nunca se chega, na qual a dor protagoniza a lembrança de um corpo humano, precário e deficitário em atingir ideais vislumbrados.

\section{Referências}

AZEVEDO, D. C.; SAMULSKI, D. M. Análise de técnicas psicológicas de controle da dor: um estudo comparativo entre atletas e não-atletas. Revista Brasileira de Medicina do Esporte, São Paulo, v. 9, n. 4, p. 204-213, 2003. Disponível em: <http://www.scielo.br/pdf/rbme/v9n4/p03v9n4.pdf>. Acesso em: 1 jun. 2017.

BECK, A. T.; ALFORD, B. A. O poder integrador da terapia cognitiva. Porto alegre: Artes Médicas, 2000.

CAMINHA, R. M.; VASCONCELLOS, J. L. C. Os processos representacionais nas práticas das TCCs. In: CAMINHA, R. M. et al. Psicoterapias Cognitivo-Comportamentais: teoria e prática. São Paulo: Casa do Psicólogo, 2003. p. 23-28.

FOULCAULT, M. O corpo utópico. In: FOULCAULT, M. O corpo utópico, as heterotopias. São Paulo: n-1, 2013. p. 7-16.

FREIRE, V. M.; PEREIRA, M. E. Crenças estereotipadas acerca de atletas que sofreram lesões. Ciências e cognição, Rio de Janeiro, v.14, n.2, p.225-234, 2009. Disponível em: <http://www.cienciasecognicao.org/revista/index.php/cec/article/view/137/91>. Acesso em: 5 abr. 2017.

GABRIELLI, L.; HOFF, T. O corpo nas imagens midiáticas que tematizam o esporte. Revista Galáxia, São Paulo, n. 14, p. 111-121, 2007. Disponível em: 
<https://revistas.pucsp.br/index.php/galaxia/article/view/1481/952>. Acesso em: 27 mar. 2017.

GONÇALVES, M. C.; TURELLI, F. C.; VAZ, A. F. Corpos, dores, subjetivações: notas de pesquisa no esporte, na luta, no balé. Movimento, Porto Alegre, v. 18, n. 03, p. 141-158, 2012. Disponível em: <http://seer.ufrgs.br/index.php/Movimento/article/view/27166/21143>. Acesso em: 4 fev. 2018.

KNAPP, P.; BECK, A.T. Fundamentos, modelos conceituais, aplicações e pesquisa da terapia cognitiva. Revista Brasileira de Psiquiatria, São Paulo, v. 30, supl. 2, p. s54-s64, 2008 . Disponível em: $\quad<$ http://www.scielo.br/scielo.php?script=sci_arttext\&pid=S151644462008000600002\&lng=en\&nrm=iso>. Acesso em 11 Fev. 2018.

LIMA, L. T.; RUBIO, K. O atleta e a experiência da hospitalização. Revista Brasileira de Psicologia do Esporte, São Paulo, v.6, n. 3, p. 90-101, 2016. Disponível em: $<$ https://portalrevistas.ucb.br/index.php/RBPE/article/view/7581/4738>. Acesso em: 10 maio 2017.

NEVES, C. M et al. Insatisfação corporal e comportamento alimentar em atletas de esportes estéticos: uma revisão. Pensar a Prática, Goiânia, v. 18, n. 4, p. 922-936, 2015. Disponível em: https://www.revistas.ufg.br/fef/article/view/37389/19791. Acesso em: 10 ago. 2017.

PINHEIRO, M. C. et al. Experiências de dor e lesão no desporto feminino. Movimento, Porto Alegre, v. 17, n. 04, p. 101-121, 2011. Disponível em: <http://www.seer.ufrgs.br/index.php/Movimento/article/view/17487/14957>. Acesso em: 6 fev. 2018.

REIS, A. C.; ZANELLA, A. V. A constituição do sujeito na atividade estética da dança do ventre. Psicologia \& Sociedade, Florianópolis, v. 22(1), 2010, p. 149-156. Disponível em: <http://www.scielo.br/pdf/psoc/v22n1/v22n1a18.pdf>. Acesso em: 4 jun. 2017.

RODRIGUEZ, A. D. Se dói é porque você está treinando bem. A sensação paradoxal de dor corporal em academias de fitness em ciudad autónoma de Buenos Aires. Movimento, Porto Alegre, v. 23, n. 2, p. 743-754, de 2017. Disponível em: <http://www.seer.ufrgs.br/Movimento/article/viewFile/70543/42228>. Acesso em 4 fev. 2018.

RUBIO, K. Psicologia, esporte e valores olímpicos. São Paulo: Casa do Psicólogo, 2012. SILVA, A. C.; FERREIRA, J. Homens no "limite" das dores na musculação de uma academia de ginástica de bairro popular: uma etnografia sobre formas plurais de expressão da masculinidade. Movimento, Porto Alegre, v. 22, n. 1, p. 89-98, 2016. Disponível em: < http://www.seer.ufrgs.br/index.php/Movimento/article/view/54670/36520>. Acesso em: 1 fev. 2018.

SILVA, E. M.; RABELO, I.; RUBIO, K. A dor entre atletas de alto rendimento. Revista Brasileira de Psicologia do Esporte, São Paulo, v.3, n.1, p.79-97, 2010. Disponível em: $<$ http://pepsic.bvsalud.org/scielo.php?script=sci_arttext\&pid=S198191452010000100006\&ln $\mathrm{g}=\mathrm{pt \& nrm}=\mathrm{iso}>$. Acesso em: 23 mar. 2017. 
THOMAZINI, S. O.; MORAES, C. E. A.; ALMEIDA, F. Q. Controle de si, dor e representação feminina entre lutadores (as) de mixed marcial arts. Pensar a Prática, Goiânia, v. 11, p. 281-290, 2008. Disponível em: <https://www.revistas.ufg.br/fef/article/view/4992/4974>. Acesso em: 3 fev. 2018.

TORRI, G.; BASSANI, J. J.; VAZ, A. F. Dor e tecnificação no contemporâneo culto do corpo. Pensar a Prática, Goiânia, v. 10, p. 261-273, 2007. Disponível em: <https://www.revistas.ufg.br/fef/article/view/1114/1692>. Acesso em: 2 fev. 2018.

VILLAÇA, N. Os imageiros do contemporâneo: representações e simulações. In: VELLOSOM, M. P.; ROUCHOU, J.; OLIVEIRA, C. Corpo: identidades, memórias, subjetividades. Rio de Janeiro: Mauad, 2009. p. 31-39.

WOLFF, A.A. Pensamento campeão: melhorando o desempenho esportivo por meio da preparação mental. Rio de Janeiro: Editora Cognitiva, 2015.

Recebido em: 29/11/2017

Revisado em: 26/01/2018

Aprovado em: 08/03/2018

Endereço para correspondência:

ricardopadovani@yahoo.com.br

Ricardo da Costa Padovani

Universidade Federal de São Paulo

Campus Baixada Santista

Departamento de Saúde, Educação e Sociedade.

Endereço: Rua Silva Jardim, 136 - Vila Mathias

Santos/SP - CEP: 11015-020 